\title{
Relative production of tumour necrosis factor $\alpha$ and interleukin 10 in adult respiratory distress syndrome
}

\author{
Lynne Armstrong, Ann B Millar
}

\begin{abstract}
Background - The adult respiratory distress syndrome (ARDS) may be regarded as an example of an uncontrolled or excessive inflammatory response in which tumour necrosis factor $\alpha$ (TNF- $\alpha$ ) has been proposed to play a central role. Interleukin 10 (IL-10) has been identified as an important regulator of this response. The potential role for IL-10 in this context was investigated by measuring the relative production of IL-10 and TNF- $\alpha$ protein in the plasma, bronchoalveolar lavage (BAL) fluid, and alveolar macrophage culture supernatants of patients with, or at risk of developing, ARDS.
\end{abstract}

Methods-Twenty six patients were studied from three groups at risk of or with ARDS: sepsis $(n=12)$, multiple trauma $(n=8)$, and perforated bowel $(n=6)$. Ten patients had ARDS. Bronchoalveolar lavage and venepuncture were performed within 24 hours of arrival on the intensive therapy unit or of diagnosis of ARDS. IL-10 and TNF- $\alpha$ protein were detected in the plasma, BAL fluid, and alveolar macrophage supernatants by sandwich enzyme linked immunoabsorbent assays.

Results - The median IL-10 concentrations in the plasma and BAL fluid of patients with ARDS were significantly lower than the concentrations detectable in the plasma (median difference $-17.5,95 \%$ CI -52.4 to $1.31, p<0.05)$ and BAL fluid of at risk patients (median difference -32.1 , $95 \%$ CI -47.5 to $2.3, \mathrm{p}<0.05$ ). There was a tendency towards enhanced concentrations of TNF- $\alpha$ detectable in the alveolar macrophage supernatants and the BAL fluid of patients with ARDS compared with at risk patients, although this did not reach statistical significance. No difference was observed in the plasma concentrations of TNF- $\alpha$ between the two groups. The ratios of TNF- $\alpha$ to IL-10 protein in the BAL fluid of patients with ARDS and at risk patients were 3.52 and 0.85 , respectively (median difference $1.44,95 \%$ CI 0.07 to $5.01, p<0.01)$. There was no difference in alveolar macrophage production of IL-10 between the two groups. Conclusions - This study highlights the potential importance of the pro-inflammatory versus the anti-inflammatory imbalance in ARDS which may be re- flected by the ratio of IL-10 and TNF- $\alpha$ in the lung.

(Thorax 1997;52:442-446)

Keywords: adult respiratory distress syndrome, interleukin 10, tumour necrosis factor $\alpha$.

The adult respiratory distress syndrome (ARDS) $)^{1-5}$ is characterised by pathological changes in the pulmonary vascular endothelium leading to neutrophil alveolitis, ${ }^{6}$ increased permeability ${ }^{7}$ and, ultimately, pulmonary fibrosis. ${ }^{8}$ This process can occur in the lung as the result of an array of initiating events, but with sepsis as a possible linking factor. It has been proposed that ARDS is the outcome of an uncontrolled inflammatory response. Hitherto, research in this field has concentrated on attempts to identify pro-inflammatory mediators which may be involved, such as tumour necrosis factor $(\mathrm{TNF})^{9}$ and interleukin 8 (IL8), ${ }^{10}$ although it has long been recognised that cytokines do not act in isolation but as part of a complex network. The roles of anti-inflammatory cytokines and binding proteins/ circulating receptors have recently been identified as a part of the normal homeostatic mechanisms. ${ }^{211-14}$ Interleukin 10 (IL-10) was originally described as a product of $\mathrm{B}$ cells but has since been shown to be produced by a number of cells, including human peripheral blood monocytes, where TNF- $\alpha$ itself has been shown to induce IL-10 production. ${ }^{15}$ IL-10 has been shown to inhibit the production of IL-1 and TNF- $\alpha$, in addition to upregulating TNF receptors. ${ }^{1617}$ It has also been shown to be produced by human alveolar macrophages at low levels, thus it is ideally suited to a regulatory role in the pulmonary inflammatory response. ${ }^{18}$ In human studies plasma IL-10 levels have been related to the outcome of septicaemia. ${ }^{19}$ We hypothesised that the relative production of IL- 10 and TNF- $\alpha$ would be altered in ARDS, reflecting the potential importance of the pro-inflammatory versus anti-inflammatory homeostatic imbalance in this condition.

\section{Methods}

PATIENTS

Patients were studied in three groups associated with the development of ARDS: bowel perforation $(n=6)$, multiple trauma $(n=8)$, and sepsis syndrome $(n=12)$. They were studied on admission to the intensive therapy units (ITUs) at the Royal United Hospital, Bath and 
Southmead Hospital, Bristol. The study was approved by the ethics committees at both centres. The extent of injury to trauma patients was assessed by the Injury Severity Score (ISS). ${ }^{20}$ An ISS score of $>15$ was used to define multiple trauma. Sepsis syndrome was defined according to the criteria of Bone $e t$ al. ${ }^{21}$ Patients were defined as having ARDS or as being at risk of ARDS on the basis of the Lung Injury Score (LIS) as defined by Murray. ${ }^{4}$ Chest radiographic infiltrates, pulmonary compliance, the ratio of arterial oxygen concentration and positive end expiratory pressure were scored on a scale of $1-4$. The LIS was calculated by dividing the total score by the number of criteria used, a score of more than 2.5 being used to define ARDS. The median LIS score for the at risk patients was 1.5 (range $1-2$ ) and that of the patients with ARDS was 3.0 (range 2.67-3.67). Patients were studied within 24 hours of arrival on the ITU and all were mechanically ventilated at the time of study. There were 16 patients at risk of ARDS and 10 with ARDS, with no significant difference between the two groups in the time between onset of illness and bronchoscopic examination.

BRONCHOALVEOLAR LAVAGE (BAL)

Each bronchoscopic examination was performed through an indwelling endotracheal tube. Bronchoalveolar lavage (BAL) was performed in the right middle lobe. All the bronchoscopies were done by one physician (AM). The chilled BAL fluid was strained through a single layer of coarse gauze to remove mucus clumps and then spun at $400 \mathrm{~g}$ for 10 minutes to recover cells. The resultant cell free fluid was stored at $-70^{\circ} \mathrm{C}$ until analysis. The alveolar macrophages were purified by negative selection with magnetic beads using granulocytespecific anti-CD66b (Serotec) and T cell-specific anti-CD3 antibodies (Dynal). Minimal binding of alveolar macrophages was observed. The resultant population was more than $98 \%$ pure and $95 \%$ viable (estimated by Diffquick staining and Trypan Blue exclusion). Alveolar macrophages were cultured for 24 hours at $37^{\circ} \mathrm{C}$ in $5 \%$ carbon dioxide in the presence or absence of lipopolysaccharide (LPS) in serum-free RPMI 1640 medium (Sigma) supplemented with $100 \mathrm{U} / \mathrm{ml}$ penicillin and $100 \mu \mathrm{g} / \mathrm{ml}$ streptomycin (Gibco). Supernatants were stored at $-70^{\circ} \mathrm{C}$ until required.

At the time of bronchoscopy, $50 \mathrm{ml}$ of blood was taken from each subject. Plasma was separated by centrifugation and stored at $-70^{\circ} \mathrm{C}$ for future analysis. We have found no differences in the immunoreactivity of samples whether analysed immediately or after such storage for up to two years.

MEASUREMENT OF IL-10 AND TNF- $\alpha$

Extracellular immunoreactive IL-10 was quantified by an enzyme linked immunoabsorbent assay (ELISA). Microtitre plates (NUNC Maxisorp) were coated with a rat anti-human IL-10 monoclonal antibody (Pharmingen). After a washing stage, diluted samples and IL-
10 standards (courtesy of DNAX) were added in duplicate and incubated for two hours at $37^{\circ} \mathrm{C}$. Biotinylated rat anti-human IL-10 monoclonal antibody (Pharmingen) was used as a detecting antibody. IL-10 levels were determined by colorimetric analysis using avidin peroxidase. This assay had a detection limit of $1 \mathrm{pg} / \mathrm{ml}$.

Extracellular unbound immunoreactive TNF- $\alpha$ was quantified by a double sandwich ELISA as previously described ${ }^{22}$ (courtesy of Celltech, Slough, UK).

DATA ANALYSIS

The data, which were not normally distributed, were compared using two sample, one tailed Mann-Whitney U/Wilcoxon ranked sum test analysis and Spearman rank correlation coefficient (Minitab package). A p value of $<0.05$ was considered significant.

\section{Results}

Twenty six patients were investigated within 24 hours of arrival on the ITU and plasma and BAL fluid were obtained. Sufficient alveolar macrophages for culture were obtained from at least five subjects in each group. There was no significant difference in the time between the onset of illness and admission to the ITU for either patient group. The statistical significance observed between patients with ARDS and those at risk of ARDS in terms of BAL fluid concentrations of IL-10 was dependent upon the inclusion of four at risk subjects who presented with perforated bowel. However, there were no discriminating features which would permit exclusion of these subjects other than their presentation. The remaining data, although influenced by these four patients, were not reliant upon them for statistical significance.

\section{TNF- $\alpha$ PRODUCTION}

There was a trend towards an increase in the concentration of TNF- $\alpha$ in the BAL fluid of the 10 patients with ARDS compared with those at risk of ARDS ( $n=10$; fig 1$)$ and there

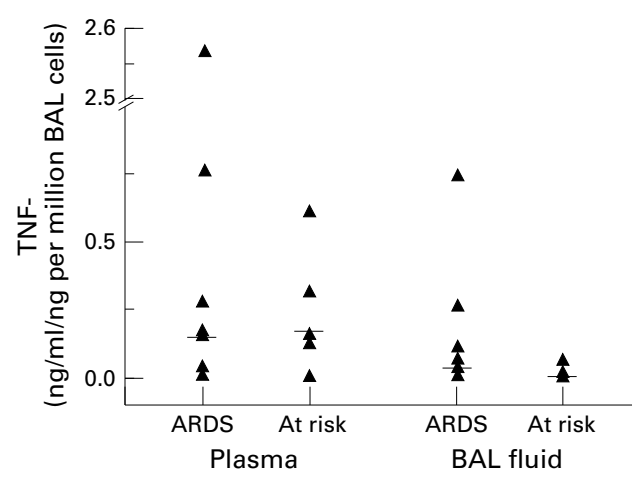

Figure $1 T N F-\alpha$ levels in the plasma and bronchoalveolar lavage (BAL) fluid of patients with $A R D S$ and those at risk of ARDS $(n=10)$. Protein levels in BAL fluid are adjusted to ng per million cells recovered by $B A L$. 


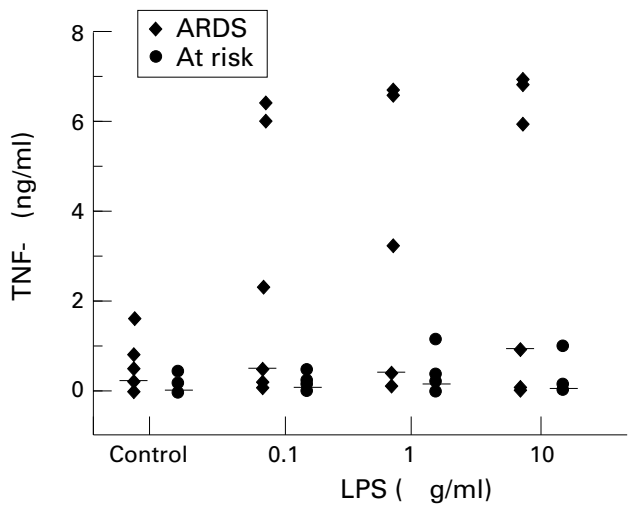

Figure $2 T N F-\alpha$ levels in the alveolar macrophage supernatants of patients with ARDS and those at risk of $A R D S(n=5)$ in response to a dose range of

lipopolysaccharide (LPS) or with medium alone (control).

was a similar finding for spontaneous and LPSinduced TNF- $\alpha$ production by alveolar macrophages $(n=5$; fig 2$)$. These data did not reach statistical significance. Plasma concentrations of TNF- $\alpha$ were similar for both groups.

\section{IL-10 PRODUCTION}

IL-10 levels detectable in the plasma of patients with ARDS $(n=10)$ were significantly lower than the IL-10 levels detected in the plasma of at risk patients $(n=16)$ (median difference $-17.5,95 \% \mathrm{CI}-52.4$ to $1.31, \mathrm{p}<0.05$ ). Similarly, IL-10 levels detectable in the BAL fluid of patients with ARDS were significantly lower than in the BAL fluid of at risk patients (median difference $-32.1,95 \%$ CI -47.5 to 2.3 , $\mathrm{p}<0.05$; fig 3). There was no difference in IL10 production by alveolar macrophages $(n=5)$ between the two groups (fig 4).

CORRELATION BETWEEN DETECTABLE LEVELS OF IL-10 AND TNF- $\alpha$ IN BAL FLUID

The levels of TNF- $\alpha$ in the BAL fluid were compared with the corresponding levels of IL10 for each patient using the Spearman rank correlation. There was a significant positive correlation between IL-10 and TNF- $\alpha$ levels

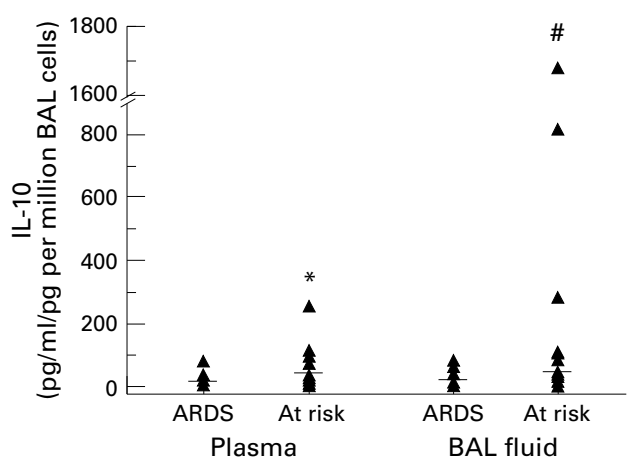

Figure 3 IL-10 levels in the plasma and bronchoalveolar lavage (BAL) fluid of patients with ARDS $(n=10)$ and those at risk of ARDS $(n=16) .{ }^{*} p<0.05$, median difference $-17.5,95 \% C I-52.4$ to 1.31 . \# $p<0.05$, median difference $-32.1 ; 95 \% \mathrm{CI}-47.5$ to 2.3 (Wilcoxon analysis). Protein levels in BAL fluid are adjusted to pg per million cells recovered by $B A L$.

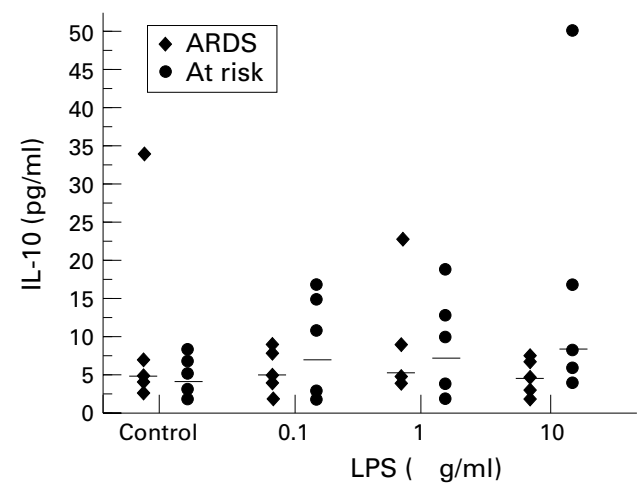

Figure 4 IL-10 levels in the alveolar macrophage supernatants of patients with ARDS and those at risk of $A R D S(n=5)$ in response to a dose range of lipopolysaccharide (LPS) or with medium alone (control).

detectable in the BAL fluid of both patients with ARDS and those at risk of ARDS ( $p<0.01$ and $\mathrm{p}<0.001$, respectively). There was no correlation between concentrations of IL-10 or TNF- $\alpha$ and survival (not shown).

RATIO BETWEEN TNF- $\alpha$ AND IL-10 IN THE BAL FLUID

The relative concentrations of TNF- $\alpha$ and IL10 in the BAL fluid of both patient groups were calculated. The ratio of TNF- $\alpha$ to IL-10 in the BAL fluid of patients with ARDS was 3.52 compared with a ratio of only 0.85 in at risk patients (median difference 1.44, 95\% CI 0.07 to $5.01, \mathrm{p}<0.01)$.

\section{Discussion}

It is widely recognised that ARDS results from the interplay of complex inflammatory processes, and pro-inflammatory cytokines may have an important role. Previous reports have suggested a pathogenic role for TNF- $\alpha$ in ARDS,${ }^{9}$ although this has recently been disputed. ${ }^{23}$ The current findings demonstrate a tendency towards increased TNF- $\alpha$ production by alveolar macrophages from ARDS patients compared with at risk patients, and this is reflected in the BAL fluid, although it did not reach statistical significance. By contrast, concentrations of IL-10 in the BAL fluid and plasma of subjects with ARDS are significantly lower than in those at risk of ARDS. Capillary leakage is a potential source of mediators in the lung compartment of patients with lung injury and ARDS, but IL-10 levels in the BAL fluid were greater than in the corresponding plasma values, although the difference was not significant. This finding, in addition to the detection of IL-10 in the alveolar macrophage supernatants, suggests that IL-10 in the BAL fluid is probably intrapulmonary in origin. The data presented here have identified the alveolar macrophage as a potential source of pulmonary IL-10, but the similarity of IL-10 production by alveolar macrophages in both groups does suggest that other sources such as human bronchial epithelial cells ${ }^{18}$ and, possibly, $\mathrm{T}$ cells $^{16}$ may be responsible for the differences seen 
in the BAL fluid. These data illustrate the imbalance between pro-inflammatory and antiinflammatory factors in the development of ARDS.

IL-10 has been shown to inhibit pro-inflammatory cytokine release ${ }^{16}$ and to downregulate class II $\mathrm{MHC}$ and $\mathrm{B} 7$ which are important molecules in antigen presentation ${ }^{2425}$ and is thus presumed to have a largely antiinflammatory role. In vitro IL-10 inhibits several functions of monocytes and macrophages, including production of TNF- $\alpha$ and $\mathrm{IL}-1,{ }^{16}$ and in animal models of endotoxaemia IL-10 is produced and reduces LPS toxicity. ${ }^{26}$ In the clinical setting IL-10 levels are increased in diseases such as septicaemia, the highest plasma levels of IL-10 being present in those with septic shock ${ }^{19}$ and rheumatoid arthritis ${ }^{27}$ where its inhibition by anti-IL-10 antibody in synovial cell cultures leads to increases in active TNF$\alpha$ and a potential exacerbation of the inflammation. This suggests that IL-10 may have a protective effect in inflammatory disease. This finding is supported by a recent study by Donnelly et $a l^{28}$ which found that increased levels of IL-10 in the BAL fluid of patients with ARDS correlated with patient survival. Hence, it may be the case here that patients with low levels of IL-10 had less adequate control of their inflammatory response to trauma and were therefore more likely to develop ARDS. We have not found such a correlation. Donnelly et al studied 25 patients with ARDS compared with only 10 in our study, so it may be that we had insufficient patients in our group. We did, however, include an at risk population which also failed to demonstrate a correlation with survival despite higher patient numbers $(\mathrm{n}=16)$.

Many studies have implicated an uncontrolled inflammatory response in the pathogenesis of ARDS. ${ }^{1-5}$ The mechanisms by which the inflammatory response occurs and is controlled have been most widely studied in the context of the sepsis syndrome and by in vitro and animal model studies of endotoxic/bacterial LPS toxicity. ${ }^{2930}$ In such studies it has been established that TNF- $\alpha$ is one of the earliest pro-inflammatory mediators which is capable of inducing many of the clinical manifestations of ARDS. We and others have previously suggested that the presence of TNF$\alpha$ in the BAL fluid of patients with ARDS plays a pathogenic role. ${ }^{9}$ In those patients studied the intrapulmonary levels of TNF- $\alpha$ were increased compared with the plasma, suggesting a pulmonary source, and this study supports this view. A recent study by Pugin et $a l^{23}$ has suggested that most of the inflammatory effects are mediated through bio-active IL-1. However, pro-inflammatory effects were determined using a complex in vitro cell culture system which may not reflect in vivo activity. Also, this study did not take into account the presence of proteolytic enzymes contained in BAL fluid which may affect the activity of TNF- $\alpha$ in this system by cleaving cell surface receptors. The activity of TNF- $\alpha$ is thought to be inhibited by the production of natural antagonists such as soluble TNF receptors and subsequently IL-
$10,{ }^{1213}$ and it is assumed that such tightly regulated homeostatic mechanisms are crucial to the prevention of pathological consequences of inflammation. We have previously shown that IL-10 can inhibit TNF- $\alpha$ production by human alveolar macrophages and peripheral blood monocytes $^{22}$ acting, at least in part, by downregulating gene transcription of $\mathrm{TNF}-\alpha \mathrm{mRNA}$ in response to LPS. This study demonstrates a positive correlation between IL-10 and TNF$\alpha$ production in both patient groups, but there is a clear distinction between the two groups since there is a larger ratio of $\mathrm{TNF}-\alpha$ protein to IL-10 protein in the BAL fluid from patients with ARDS, favouring a pro-inflammatory process. The data presented highlight the importance of the imbalance between pro-inflammatory and anti-inflammatory activity in ARDS. Longitudinal studies of at risk subjects with repeated lavage are required to be anything more than speculative on the role of IL-10 in this clinical scenario.

Lynne Armstrong is supported by Southmead NHS Trust Bristol, UK. We would like to thank Dr Gordon Paul (University of Bristol, Department of Clinical Veterinary Science) for statistical advice and Sharon Standen for editorial advice.

1 Rinaldo JE, Rogers RM. ARDS: changing concepts of lung injury and repair. $N$ Engl f Med 1982;306:900-10.

2 Cassatella MA, Meda L, Bonora S, Ceska M, Constantin G. IL-10 inhibits the release of pro-inflammatory cytokines from human polymorphonuclear leukocytes. $\mathcal{f} \operatorname{Exp} \mathrm{Med}$ 1993;178:2207-11.

3 Ashbaugh DG, Bigelow DB, Petty TL, Levine BE. Acute respiratory distress in adults. Lancet 1967;ii:319-23.

4 Murray JF, Matthay MA, Luce JM, Flick MR. An expanded definition of the ARDS. Am Rev Respir Dis 1988;138: definition.

5 Rocker GM, Wiseman MS, Pearson D, Shale DJ. Diagnostic criteria for ARDS: time for re-appraisal. Lancet 1989; $120-3$.

6 Tate RM, Repine JE. Neutrophils and the ARDS. Am Rev Respir Dis 1983;128:552-7.

7 Braude S, Nolop KB, Hughes JMB, Barnes PJ, Royston D. Comparison of lung vascular and epithelial permeability indices in the ARDS. Am Rev Respir Dis 1986;133:1002-5.

8 Pratt VC, Vollmer RT, Shelburne JD, Crapo JD. Pulmonary morphology in a multi-hospital collaborative extra-corporeal membrane oxygenation project. Am f Pathol 1979; 95:191-214.

9 Millar AB, Singer M, Foley NM, Johnson NM, Rook GA TNF in bronchopulmonary secretions of patients with ARDS. Lancet 1989;ii:712-4

10 Miller EJ, Cohen AB, Nagao S, Griffith D, Mande RJ, Martin TR, et al. Elevated levels of NAP-1/IL-8 are present in the airspaces of patients with the ARDS and are associated with increased mortality. Am Rev Respir Dis 1992;146:427-32

11 Lantz M, Gullberg U, Nilsson E, Olsson I. Characterisation in-vitro of a human TNF-binding protein. A soluble form in-vitro of a human TNF-binding protein. A soluble

12 Spinas GA, Keller U, Brockhaus M. Release of soluble receptors for TNF in relation to circulating TNF during experimental endotoxinemia. $\mathcal{F}$ Clin Invest 1992;90:533-6.

13 Aderka D, Engelmann H, Maer Y, Brakebusch C, Wallach D. Stabilisation of the bioactivity of TNF by its soluble receptors. F Exp Med 1992;175:323-9.

14 de Waal Malefyt R, Figdor CG, Huijbens R, Mohan-Peterson S, Bennet B, Culpepper J, et al. Effects of IL-13 on phenotype, cytokine production and cytotoxic function of human monocytes. Comparison with IL-4 and modulation by IFN-gamma or IL-10. F Immunol 1993;151: 6370-81.

15 Wanidworanun C, Strober WJ. Predominant role of TNF$\alpha$ in human monocyte IL-10 synthesis. F Immunol 1993; 151:6853-61.

16 Ralph P, Nakoinz I, Sampson-Johannes A, Fong S, Cone $\mathrm{D}$, Min H, et al. IL-10 T lymphocyte inhibitor of human blood cell production of IL-1 and TNF. F Immunol 1992; 148:808-14.

17 Joyce DA, Gibbons DP, Green P, Steer JH, Feldmann M, Brennan FM. Two inhibitors of pro-inflammatory cytokine release, IL-10 and IL-4, have contrasting effects on release of soluble p75 TNF receptor by cultured monocytes. Eur F Immunol 1995;24:2699-705.

18 Bonfield TL, Kenston MW, Burfeind P, Panuska JR, Hilliard JB, Berger M. Normal bronchial epithelial cells produce the anti-inflammatory cytokine IL-10, which is downregulated in cystic fibrosis. Am J Respir Cell Mol Biol 1995, 13:257-61. 
19 Marchant A, Deviere J, Byl B, De Groote D, Vincent J-L, Goldman M. IL-10 production during septicaemia. Lancet 1994;343:707-8.

20 Boyd CR, Tolson MA, Copes WS. Evaluating trauma care: the TRISS method. F Trauma 1987;27:370-8.

21 Bone RC, Fisher Jr CJ, Clemmer TP, Slotman GJ, Metz CA, Balk RA. A controlled clinical trial of high dose methylpredinisolone in the treatment of severe sepsis and septic shock. $N$ Engl f Med 1987;317:653-8.

22 Armstrong L, Jordan NJ, Millar AB. IL-10 regulation of TNF- $\alpha$ from human alveolar macrophages and peripheral TNF- $\alpha$ from human alveolar macrophages
blood monocytes. Thorax 1996;51:143-9.

23 Pugin J, Ricou B, Steinberg KP, Suter PM, Martin TR. Proinflammatory activity in bronchoalveolar lavage fluids from patients with ARDS, a prominent role for IL-1. Am f Respir Crit Care Med 1996;153:1850-6.

24 de Waal Malefyt R, Haanen J, Spits H, Roncarolo M, te Velde A, Figdor C, et al. IL-10 and viral IL-10 strongly reduce antigen specific human $\mathrm{T}$ cell proliferation by diminishing the antigen presenting capacity of monocytes via downregulation of class II major histocompatibility complex expression. f Exp Med 1991;174:915-24.
25 Ding L, Linsley DS, Huang L, Germain RN, Shervach E. IL-10 inhibits macrophage co-stimulatory activity by selectively inhibiting the up-regulation of B7 expression f Immunol 1993;151:1224-34

26 Howard M, Muchamuel T, Andrade S, Menon S. IL-10 protects mice from lethal endotoxemia. $\mathcal{F}$ Exp Med 1993; 177:1205-8.

27 Katsikis PD, Chu C-Q, Brennan FM, Maini RN, Feldmann M. Immunoregulatory role of IL-10 in rheumatoid arthritis. F Exp Med 1994;179:1517-27.

28 Donnelly SC, Strieter RM, Reid PT, Kunkel SL, Burdick M, Armstrong I, et al. The association between mortality rates and decreased concentrations of IL-10 and IL-1 receptor antagonist in the lung fluids of patients with the ARDS. Ann Intern Med 1996;125:191-6.

29 Tracey KJ, Lowry SF, Fahey TJ, Albert JD, Fong Y, Hesse $\mathrm{D}$, et al. Cachectin/TNF induces lethal shock and stress hormone response in the dog. Surg Gynecol Obstet 1987; 164:415-22.

30 Stephens KE, Ishizaka A, Larrick JW, Raffin TA. TNF causes increased pulmonary permeability and oedema. Comparison to septic acute lung injury. Am Rev Respir Dis 1988;137:1364-70. 